\title{
Assessment of the Factors of Investment Attractiveness of the Business Environment in Terms of Sustainable Development of the Region
}

\author{
Gennady Alexandrov, Irina Vyakina and Galina Skvortsova* \\ Tver State Technical University, Department of Economics and Production Management, Tver, \\ Russia
}

\begin{abstract}
It should be noted, that today the world scientific community try to find new ways of economic development, which are aimed at refusing to absolutize economic growth at the expense of solving social and ecological problems and ensuring the vital requirements of future generations. In this regard, the authors have proposed a methodological technique, that allows to systematize the factors of investment attractiveness of the business environment of the region, which are considered in terms of implementing the goals of sustainable development and increasing innovative activity. At the same time, we consider it necessary to emphasize, that the use of the obtained research results will allow, in our opinion, to significantly advance both in theoretical and practical terms in solving the development and implementation of reasonable interim measures to advance the region towards achieving sustainable development goals.
\end{abstract}

\section{Introduction}

The scientific community is widely discussing the need to form new economic models within the paradigm of sustainable development of mankind and the world economy, taking into account the increasing imbalance of global economic, social and ecological trends. New economic models are reflected in scientific works and in strategic documents of various states and private business, including in the Russian Federation.

Today, the principles of sustainability, laid down by the UN Conference in Rio de Janeiro, are being implemented within the framework of the UN Sustainable Development Goals for 2016-2030. (Sustainable Development Goals) (SDGs), which replaced the UN Millennium Development Goals (2000-2015). At the same time, the paradox of the current situation is, that in numerous discussions of sustainable development, the world continued to develop in the direction of unsustainable development.

In the process of social development, the problem of collision of interests (of individuals, economic entities, states) in their interaction inevitably arises. Economic relations are manifested through the interests of interdependent economic entities, managing economic benefits, material, financial and labor resources. Interests underlie the motivation of individuals or social groups and the decisions, that all participants in economic life make.

\footnotetext{
*Corresponding author: gala-skvortsova@yandex.ru
} 
The investment process has an institutional nature, and acts as a system of relations between its subjects regarding the expected results of their activities: its source is economic interest, and its efficiency depends on the alignment of interests of economic entities. The basis for the renewal of capital is the desire of entrepreneurs to increase the rate of return, which gives rise to motivation and interest in investments. In this regard, the implementation of sustainable development goals, which requires additional costs, reduces the entrepreneur's profit, which is contrary to his interests. Alignment of economic interests acts as the basis for sustainable socio-economic development and an integral element of the state's economic policy, aimed at activating investment activity.

In this work, we base on the assumption, that the nature of investment processes should be consistent with the goals of sustainable development. The main difficulty of studying the problem of investment attractiveness in the context of sustainable development is, that it is impossible to limit ourselves to considering only economic factors, without taking into account the ecological and social determinants of development.

The investment attractiveness of a particular enterprise cannot be considered in isolation from the regional business environment, in which it operates. At the same time, it is obvious, that the region itself should be attractive for investment, that is, the current business conditions in it form a business environment, in which specific investment objects are investment-attractive.

\section{Research methods}

Recently, the term "ecosystem" has been used to study the interaction of economic units with the business environment. By analogy with biological ecosystems, James F. Moore in 1993 proposed to consider economic activity as an ecosystem, where economic units, interacting in the process of economic activity, equally participate in the evolution within the business ecosystem as an integrated structure of interdependent subjects, uniting enterprises, scientific organizations and government bodies, that coexist in common environment and develop together, like living beings in biological ecosystems [1].

The ecosystem approach assumes, that an enterprise develops as part of a business ecosystem. A business ecosystem, like its biological counterpart, develops, evolves and gradually moves from a random set of elements to a more structured community. The ecosystem approach in business led to the transformation of not only the theory and practice of management, but also the methodology for joint assessment of the investment attractiveness of an enterprise and the regional business environment.

In the context of the problem under study, it is proposed to assess the investment attractiveness at the regional level in terms of the ecosystem approach. The research of quantitative and qualitative factors of investment attractiveness is closely related to the parameters of the regional business environment. The factors are grouped by analogy with the classical grouping of environmental factors, adopted in the PEST analysis.

The assessment of the factors of the business environment, including their identification, is based on the principle of "factors-levels", taking into account, that the enterprise operates in a social economic hierarchical system and its investment attractiveness is due to the attractiveness of the external business environment. The use of this principle is also justified by the fact, that the factors, that determine investment attractiveness affect both the enterprise itself and the business environment, which allows solving the problem of assessing and identifying factors within the framework of a single methodological matrix approach to assessing factors, that appear at different levels of operation of the economic system.

In our view, based on the understanding, that economic processes are provided by certain production conditions (infrastructure) and specific organizational and legal relations, it is quite legitimate to present them by four main groups of factors: administrative-legal, 
economic, socio-ecological and resource-technical, which affect at four levels, the enterpriseindustry-region-national economy. For details on groups of factors, see [2].

Investment attractiveness factors are assessed at a specific level in each group. All identified determinants and factors have numerical score using an expert method. The assessment is based on the opinion of a professional group of experts and, at this step, can be carried out within any scale. For example, on a 5-point basis, in which 1 means a low level, and 5, respectively, a high level of barriers, challenges and threats. In order to increase the validity of assessments and reduce the influence of the subjective factor on them, that is, the personal opinion of experts, we consider it necessary and possible to apply the Kendall coefficient of concordance in order to determine the degree of consistency of expert assessments and rank the factors according to their degree of influence on the investment attractiveness of the object. In other words, the level of this coefficient is at least $70-80 \%$, which means a fairly high degree of agreement of experts with each other in determining the value of assessments, which, in turn, indicates the minimization of the subjective factor and a sufficiently high reliability of expert assessments.

\section{Results}

The public interests of the state are associated with ensuring sustainable economic development and a decent quality of life for the entire population of Russia, regardless of the region of residence. In addition, the characteristics of the business environment vary greatly in different regions, which leads to imbalances and disproportions in the development of the national economy. Regions, comparable in terms of their socio-economic potential, vary quite significantly in terms of investment risk parameters and in terms of institution efficiency.

This state of affairs testifies to the presence of systemic problems in the Russian business environment, which require qualitatively new tools for identifying and assessing threats, contributing to the selection and justification of investment management mechanisms.

The enterprise, as the key link of the system, is the main object of investment. The investment attractiveness of an enterprise in terms of economic factors is the investor's subjective perception of specific economic conditions, which determine his motivation to invest. Thus, the investor assesses the economic feasibility of the investment decision.

With that, it should be borne in mind, that the investor, before making a decision to invest, assesses the economic situation in the industry, its prospects, the nature of the economic strategy, positioning in the region and the national economy, etc. Territorial factors and regional affiliation of the investment object also have a significant influence on the investor's decision to invest.

If we consider the methodology for assessing the attractiveness of an investment object from the standpoint of implementing the concept of sustainable development, it can be noted, that despite the variety of solutions, proposed by the scientific community, in our opinion, the system of methods for assessing investment attractiveness lacks a clear algorithm for comparative analysis and assessment of internal and external risks, related to the constraints, imposed by the Sustainable Development Goals. In addition, the existence of a close interrelation between the investment climate of the country, region, investment attractiveness of the industry, enterprises is not taken into account.

We note, that the difference in assessment purposes, pursued by individual parties of the investment process, leaves stamp on the interpretation of the results obtained. Most of the existing methods are based on an approach to determining the investment attractiveness of an enterprise from the position of an investor, while at the present time, it is gaining importance, that the management of enterprises have the opportunity to independently assess the investment attractiveness of their enterprise and identify the most significant investment 
risks. Difficulties in the opportunity to take into account and assess all the risks, that the enterprise will face in the foreseeable future, pose risks to the quality of long-term forecasts.

All of the above necessitates the development of new approaches to identifying key threats in the investment sphere, understanding the processes, related to changes in social, ecological and economic relations, substantiating the system of investment attractiveness factors, an algorithm for identifying key factors and creating a fundamentally new diagnostic method for assessing investment risk.

In this regard, the authors proposed a methodological technique, that allows to systematize the factors of investment attractiveness of the business environment of the region in their interrelation with the level of investment risk. This sixteen cell matrix is a formalized expression of the interrelation between two measurement systems. The first one is a combination of various factors, that determine the nature of the investment climate and are distributed into four groups (administrative and legal; economic; socio-ecological and resource-technical). The second one reflects the levels of the economic hierarchy, at which these factors are manifested and modified (Fig. 1).

Next, we will consider the manifestation of each of the listed factors of the business environment in the practice of doing business and highlight the features of each of the enlarged groups of factors, related to the implementation of sustainable development goals.

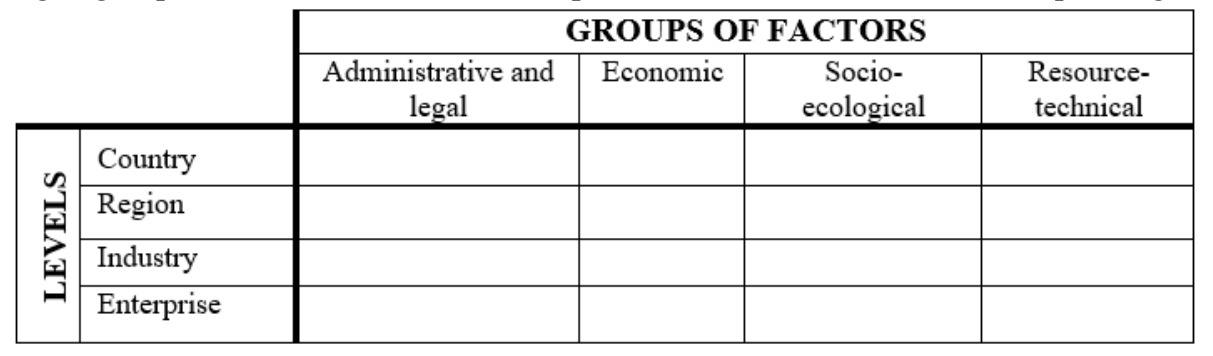

Fig. 1. Matrix of distribution of factors of investment attractiveness of the business environment by groups and corresponding hierarchical levels (Source: Authoring)

Administrative and legal factors of the regional business environment have a pronounced institutional nature. The administrative conditions of the business environment can be considered as an developed system of relations between business entities and government authorities, that exercise control, supervisory, regulatory and licensing functions and determine key directions of economic policy, including those, that form conditions for the implementation of sustainable development goals. As noted by N.Z. Solodilova, R.I. Malikov and K.E. Grishin, it is the administrative factors, that determine the level of the fiscal burden and the withdrawal of part of the entrepreneurial income from business entities [3, p. 134].

Since administrative regulation is formed within a certain legal field, in this context it seems expedient to consider not just the regulatory functions of the state, but legislative and legal acts. A.A. Porokhovsky [4, p. 57] argues, that "public interests are expressed through laws or other state acts, adopted by the state, for direct or indirect regulation of the market environment, which they need for their own preservation and development".

In the standards of financial and tax law, a protective mechanism of public interests is provided, therefore, in this aspect, financial and tax law act as an institutional standard regulator and a tool for alignment of interests and the main mechanism for the practical implementation of the principles, laid down in the concept of sustainable development.

Economic and financial factors are related to the market and financial conditions of the business environment. The volume and specificity of the market; fiscal burden, availability of credit resources, development of the financial system, etc. are such characteristics of the business environment. 
It is obvious, that the investment activity of an entrepreneur and the attractiveness of the regional business environment depend on the prevailing rules of the game, under which $\mathrm{W}$. Baumol indirectly understood the "economic structure of rewarding entrepreneurial efforts" due to the "structure of payments of economic units" [6, p. 319]. The structure of payments, including the stream of revenue and payments of economic units, determines "the ratio of benefits and costs, obtained as a result of economic activity, including the use of informal schemes".

The need for a transition to a circular economy, focused on the utilization and recycling of waste, is recognized in the world and in Russia. However, as noted by the authors of the article [5], the cost of circular technologies is quite high. Due to the high financial risk, banks are often reluctant to fund innovative ideas. Therefore, for the development of new innovative technologies, based on the principles of sustainable development, financed by business, it is necessary to minimize financial risks. Ecological restrictions lead to an increase in the cost of ensuring ecological standards of production and consumption.

The decisions, taken in recent years in Russia, aimed at creating a waste industry, are one of the first steps towards a circular economy. For example, the planned construction of waste incinerators requires significant investments and causes a negative reaction among the population, living in the surrounding areas.

Socio-ecological factors of the regional business environment are associated, among other things, with national mental, political and social factors, as well as the ecological situation. In the conditions of social contrasts, the absence of a well-functioning and resistant to different threats health system, even progressive developments in the field of medicine will not be able to stop the spread of new epidemic diseases.

It is obvious, that future development is impossible without preserving the integrity of natural systems, maintaining their life-supporting functions, improving the quality of life, improving the health of the population and the demographic situation.

At the same time, as B.N. Porfiriev [7, p. 4] notes, the threats to the development of the economy of the Russian Federation in the long term are associated with the qualitative level of development of technologies, which, on the one hand, increase the risks of a significant weakening of Russia's competitive positions in the world market (due to the inconsistency of the manufactured products with environmental and climatic standards for product quality), on the other hand, they contribute to the increased risks of deterioration in the quality of human capital and population health due to a decrease in the quality of the environment. This refers to technologies, that ensure deep and complete recycling of natural resources and their use in a wasteless closed production cycle, allow to reduce the negative impact on ecosystems and reduce the risks of their degradation. The lack of such technologies in Russia, according to the author, is evidenced by the extremely low level of resource efficiency of primary resources, including energy and water resources, as compared to the leading economies, as well as the low specific weight of industrial waste recycling. In his understanding, sustainable development, competitiveness of the economy and ensuring the security of the national innovation base are based on the interdependence of economic and ecological imperatives [7, p. 6].

At the moment, developed countries are focusing on reducing the consumption of traditional hydrocarbons and transition to renewable energy sources, which is supported by state economic policy through taxes, loans, subsidies, etc. On the part of the main consumers of energy resources of the European Union and China, as part of the transition to a lowcarbon model, the consumption of traditional hydrocarbons is decreasing and the specific weight of renewable energy sources is increasing. In Russia, despite attempts to reduce the energy intensity and improve energy efficiency, energy costs per unit of the final result remain one of the highest in the world, exceeding rational levels by $2-3$ times [8, p. 14-15]. 
Meanwhile, the assessment by entrepreneurs of the efficiency of their economic activities, their perception of risk and their combination determine the logic of decision-making in the business environment [9, p. 272].

The resource-technical and infrastructural factors of the regional business environment determine the technical, technological and infrastructural conditions for investment activity. The unsatisfactory condition of the transport, energy and financial infrastructure creates serious barriers and restrictions for the investor.

In addition to transport, energy and public utility infrastructure, the conditions for the functioning of a business are determined by the level of development of digital and information infrastructure, that provides information interaction and communication between subjects of the business environment, including information, computing, telecommunication and network capacities, operating on a digital basis.

Digital technologies such as the Internet of Things, big data and new ways of data analytics are considered to be important factors, that contribute to the introduction of a closed economy, as they drive at increased resource efficiency and productivity [10]. In addition, digital technologies allow creating business models of a closed economy, since they allow individual companies in real conditions to optimize the flows of their resources, create added value, and thereby contribute to the introduction of innovations in business models [11]. New digital platforms allowed to coordinate the practice of exchange among a large number of users, expand access to a wide range of tangible and intangible resources within the framework of large and spatially distributed communities of consumers [12]. Such largescale changes, caused by digital achievement, can raise a number of important issues, regarding the implementation of the sustainable development goals, which come with both opportunities and risks.

We note, that the very idea of sustainable development was born in developed countries, that reached a fairly high level of social and economic development. As V.I. Kushlin [13, p. 157] notes, the experience of highly developed countries "cannot be reproduced on a massive scale today, in the conditions of the limiting state of the planet's resource base". As the author notes, the criteria and standards of resource consumption, achieved in the group of highly developed countries of the world, "were formed on the basis of absolutely unique historical conditions", at a time, when the "problem of limited primary resources" was not so acute.

We also note, that developing countries, whose standard of living is worlds apart, in contrast to highly developed ones, cannot invest significant funds in the implementation of the idea of sustainable development, since they are faced with the task of satisfying, first of all, the physiological and social needs of the population.

Despite a significant amount of research on the formation of effective mechanisms for the implementation of sustainable development goals, they remain quite controversial.

\section{Discussion}

The organization of the process of effective renewal of fixed assets currently seems to be a real opportunity for the technological development of the Russian economy. A variety of forms of ownership and economic interests impose new requirements to the methodology and practice of renewing fixed assets and organizing the investment process. The totality of economic interests, their unity and contradiction at different levels of economic activity determine the transformation of motivation for investment activity. The new concept of investment attractiveness of the region in the context of the implementation of sustainable development goals requires a study of the problem of motivating economic decisions, that affect investment processes and the efficiency of capital flow in order to ensure the strategic safe development of the economy. 
Undoubtedly, the business as a matter of priority chooses the way, that ensures the maximum results from its activity. However, in the context of the implementation of sustainable development goals, it is also important, how profit is maid, and what are the cofactors and bars to achieving financial and economic goals, as well as how they are measured. Sustainable Development Goals imply fixation on a win-win decision-making. This means, that, when determining the amount of profit, it is necessary to take into account the interests of all subjects of economic relations. In this case, in meeting the needs of the region in moving towards sustainable development and entrepreneurs in obtaining the expected financial and economic results. At the same time, it is understood, that doing and investing a business should, as a priority, take into account the social, ecological, human aspects and costs of its activity, including at the enterprises themselves. All that is lacking is to decide on measures of a superstructural, administrative and legal nature in order to ensure, firstly, the achievement of mutually beneficial solutions in the implementation of investment activity and, secondly, the build-up of the social and natural environment, instead of constantly exposing it to degradation

But, to a much greater extent, a group of administrative and legal factors is associated with the group of socio-ecological factors. In particular, such factors as: the socio-political situation in the region [how much stability and continuity of authority are observed; whether the relations between business and authority is partnership; how the relations between the population of the region and business is developing; how often the authority in the region changes; what is the level of compliance with law and order in the region, etc .; the adequacy of regional legislation]; the authority's willingness to reform it [the availability and quality of regulations, designed to stimulate investment; the effectiveness of tax administration and the willingness of the authority to improve it; the effectiveness of support of small and medium businesses in the region; the degree and nature of the participation of the regional authorities in practice on investments; experience in the region's implementation of large investment projects; the degree of freedom of investors in choosing regional partners; the nature of assistance and support in the implementation of projects to protect and improve the ecology; the presence of corruption and criminal risks]; the degree of independence of the regional authorities in decision-making to motivate and stimulate the implementation of social and ecological policies [the presence of bureaucratic problems, manifested in the region as administrative barriers and restrictions; the adequacy of order in the distribution of limited resources; the degree of transparency in the actions of regional authorities; the size and trends of the growth of the bureaucratic apparatus; relation to corporate conflicts and illegal seizure; the level of crime situation in the region].

\section{Conclusions}

Thus, the situation with the problem of transition to sustainable development, including in relation to the territorial (regional) level, predetermines the content of the hypothesis, which is, that the nature of investment processes should comply with the sustainable development goals. But this compliance can be ensured only if the region itself is attractive for investment, which is equal to creating an environment, in which specific investment objects are investment-attractive. Hence, the most important circumstance is the creation of conditions in the regions, firstly, to attract investments for sustainable development, and secondly, to eliminate barriers and restrictions, threats and challenges, that negatively affect the investment attractiveness of enterprises. However, at the same time, the proposed hypothesis presents an objective contradiction, the essence of which is, that in the conditions of the transition to sustainable development, the latter can be factors, on the one hand, limiting the implementation of investment activity, but, on the other hand, introduced as restrictions for solutions in the investment process of ecological and social problems. But, in the latter case, 
the hypothesis provides for the possibility of resolving this contradiction by developing adequate measures of a superstructure (organizational and economic nature), implemented within the framework of economic policy, carried out at the appropriate levels of the economic hierarchy.

It can't hurt to emphasize here, that our use of original approaches to assessing and ranking factors will allow, firstly, to make significant progress in solving the problem of minimizing the role of the subjective factor, when using the method of expert assessments. Secondly, to identify those factors that, as the rating shows, have the greatest influence on assessments of the attractiveness of a region and specific enterprises. Thirdly, to obtain information on the extent, to which the presence of barrier and restrictive factors, threats and challenges negatively affects the investment attractiveness of enterprises. It should be added, that the use of the obtained research results will allow, in our opinion, to significantly advance both in theoretical and practical terms in solving the development and implementation of reasonable measures to attract sustainable investments and advance the region towards sustainable development.

The acknowledgements: The reported study was funded by RFBR, project number 20-010-00124.

\section{References}

1. J.F. Moore. Harvard Business Review 71(3), 75 (1993)

2. G.A. Alexandrov, Investment Climate Attractiveness and Investment Risks: Methodology, Diagnostic Methods (Moscow: Creative Economy, 2020)

3. N.Z. Solodilova, K.E. Grishin, R.I. Malikov, Economic policy 13(5), 134 (2018)

4. A.A. Porokhovsky, Economic Revival of Russia 2(60), 55-61 (2019)

5. S. Yuan, H.O. Musibau, S.Y. Genç, R. Shaheen, A. Ameen, Z. Tan. Technological Forecasting and Social Change. 165 (2021)

6. W. Baumol, Microtheory of Innovative Entrepreneurship (M .: Publishing house of the Gaidar Institute, 2013)

7. B.N. Porfiriev, Problems of forecasting 5(170), 3 (2018)

8. Green Economy and Sustainable Development Goals for Russia (Moscow: Faculty of Economics, Lomonosov Moscow State University, 2019)

9. S. Stroe, V. Parida, J. Wincent, J. of Business Research 89, 265 (2018)

10. E. Kristoffersen, F. Blomsma, P. Mikalef, J. Li, J. of Business Research 120, 241 (2020)

11. V. Ranta, L. Aarikka-Stenroos, J.-M. Väisänen, Resources, Conservation and Recycling, 164 (2021)

12. M.J. Pouri, Resources, Conservation and Recycling 168 (2021)

13. V.I. Kushlin, Bulletin of the Peoples' Friendship University of Russia. Series: Economics 5, 154 (2012) 